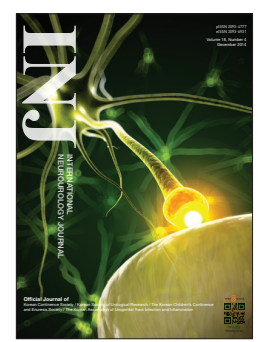

\title{
Experimental Design for Biologists. 2nd ed.
}

By David J Glass. 289 pp. Cold Spring Harbor, NY: Cold Spring Harbor Laboratory Press; 2014. \$39.00. ISBN 978-1-62182-041-3 (Hardcover)

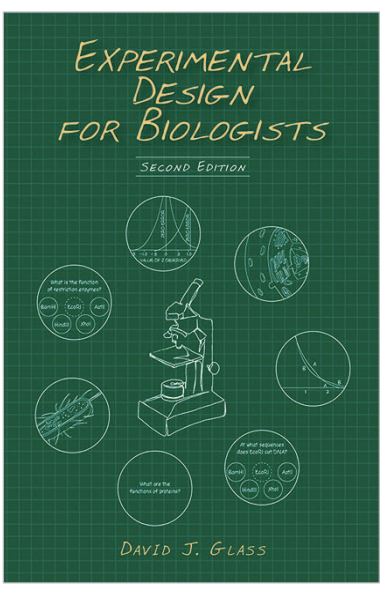

There is a pervasive atmosphere in the researching community to gloss over the philosophy of discovery and center around the 'how-to' method of easy productivity and lack of effort. This poorly titled book will fool the reader into thinking it is the latter, when it is actually a book that should be read by all who begin science in biology. The book would feign to present a step by step guide to navigate in setting up an experiment, but instead would actually provide the most important reminder as to why we do what we do. Very rarely are we treated with solid courses in the philosophy of science that touches upon all the important issues while also escapes becoming overweight in the metaphysical. While this book also touches upon some of the minutiae in considering choices of experiment design, it is primarily focused on performing the right science for the right job rather than performing the right procedure.

It is not to say that that this book is insufficient when dealing with common problems that one would expect in proceeding with designing a series of experiments to reach one's goal. It covers broad topics from statistical considerations, choices in how to tackle dosage, decisions on what level of showing the effect is sufficient, etc. However, keep in mind that eschewing the overall emphasis in what the author is trying to convey with the concept of scientific design over the technicalities, one may find it slightly lacking in the details and variety of actual examples. For instance, the reader will not find the best method cut out and posted as to how to treat siRNA, but rather will bump into the topic when discussing the best methods to set up a negative control in a general sense.

Overall, the Experimental Design for Biologists is a worthy read on the basic principles of scientific investigation. It will remind many researchers why they have set course on what they do today, as well as provide those new with guidance sorely required and rarely taught.

Jin Wook Kim

Department of Urology, Chung-Ang University College of Medicine E-mail: jinwook@cau.ac.kr 